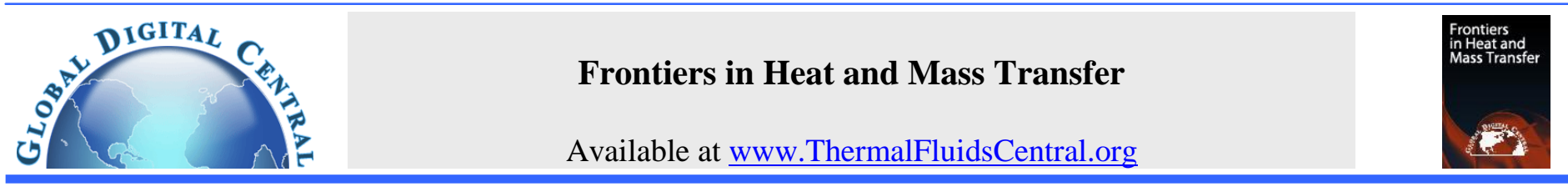

\title{
EXPERIMENTS ON DOMINANT FORCE REGIMES IN FLOW BOILING USING MINI-TUBES
}

\author{
Soumei Baba ${ }^{a,{ }^{*}}$, Nobuo Ohtani ${ }^{\mathrm{a}}$, Osamu Kawanami ${ }^{\mathrm{b}}$, Koichi Inoue $^{\mathrm{c}}$, Haruhiko Ohta ${ }^{\mathrm{a}}$ \\ ${ }^{a}$ Department of Aeronautics and Astronautics, Kyushu University, Fukuoka, Fukuoka 819-0395, Japan \\ ${ }^{b}$ Department of Mechanical and System Engineering, University of Hyogo, Himeji, Hyogo, 671-2201, Japan \\ ${ }^{c}$ Faculty of Environmental Engineering, Kitakyushu University, Kitakyushu, Fukuoka, 808-0157, Japan
}

\begin{abstract}
Effects of tube orientation on flow boiling heat transfer coefficients were investigated for FC72 flowing in single mini-tubes with tube diameters of 0.13 and $0.51 \mathrm{~mm}$ to define boundaries on a dominant force regime map. For the tube diameter of $0.51 \mathrm{~mm}$, when mass velocity and vapor quality was varied, heat transfer coefficients were influenced by tube orientation at Froude number $F r<4$, while the effect of tube orientation on heat transfer coefficients disappears at $F r>4$. The results indicated that the boundary between the body force dominated and the inertia dominated regimes was given by $F r \approx 4$. On the other hand, for tube diameter of $0.13 \mathrm{~mm}$, almost no effect of tube orientation on heat transfer coefficients was observed for all combinations of mass velocity and vapor quality tested, where heat transfer coefficients were independent of mass velocity and vapor quality at Weber number $W e<5$, and vice versa. The results indicated that the boundary between the surface tension dominated and the inertia dominated regimes was represented by $W e \approx 5$. From the above results, the boundary between the surface tension dominated and the body force dominated regimes was existed between $B o=0.51$ and 0.033 .
\end{abstract}

Keywords: Flow boiling, Heat transfer, Minichannel, Dominant force regimes

\section{INTRODUCTION}

Recent increase in the size of space platforms requires the management of larger amount of waste heat under high heat flux conditions and the transportation of it along a long distance to the radiator. Flow boiling applied to the thermal management system in space attracts much attention as a promising means to realize high-performance heat transfer and transport due to latent heat of vaporization. In microgravity two-phase flow phenomena are quite different from those under normal gravity conditions because buoyancy effects are significantly reduced and surface tension becomes dominant. By the similar reason, flow boiling characteristics in minichannels are not the same as those in channels of the normal sizes. In the present stage, however, the conditions at the boundary between the regimes of body force dominated and of surface tension dominated are not clear. The design of space thermal devices, operated under the conditions where no influence of gravity is expected, will improve the reliability of their ground tests. For this reason, the quantitative clarification of boundaries for dominant force regimes is required in advance.

Although a number of experiments on flow boiling heat transfer in minichannels were conducted in the last decade, there is limited flow boiling heat transfer data obtained by a single circular heated tube due to the difficulty of precise measurement. Tran et al. (1996) measured local flow boiling heat transfer coefficients for R12 in a single circular tube with tube diameter of $2.46 \mathrm{~mm}$. They reported that heat transfer coefficients were a function of heat flux, and that the effect of vapor quality and mass velocity was small. They concluded that nucleate boiling heat transfer dominated in a minichannel over wide vapor quality ranges of 0.2-0.8. Lazarek and Black (1982), Bao et al. (2000),
Owhaib et al. (2004), and Saisorn et al. (2010) also obtained similar results by the experiments using a single circular tube with $0.83-3.1$ $\mathrm{mm}$. Yen et al. $(2003,2006)$ measured local heat transfer coefficient for FC72 and R123 flowing in single circular tubes with $0.19-0.51 \mathrm{~mm}$. However, they observed only monotonically decreasing trend of heat transfer coefficient with increasing vapor quality. Lin et al. (2001) measured local heat transfer coefficient for R141b flowing upward in a vertical $1.1 \mathrm{~mm}$ circular tube. Unlike the aforementioned experiments, they observed a significant influence of vapor quality on heat transfer coefficient. At low heat fluxes, the heat transfer coefficient increased consistently with increasing vapor quality. At moderate heat fluxes, the heat transfer coefficient became independent of vapor quality. At high heat fluxes, the heat transfer coefficient took a peak value just after the initiation of nucleate boiling and followed by a consistent decrease. Shiferaw (2009) also obtained similar results by the experiments using a single circular tube with $1.1 \mathrm{~mm}$. Saitoh et al. (2005) conducted flow boiling experiments of R134a flowing in single circular tubes with 0.51-3.1 $\mathrm{mm}$. In the experiments using smaller tubes, they also observed a trend of increase in heat transfer coefficient with increasing vapor quality at lower vapor quality and a trend of decrease at high vapor quality. The decrease in heat transfer coefficient began at lower vapor quality for smaller tube. In and Jeong (2009) measured local heat transfer coefficient for R123 and R134a flowing upward in a $0.19 \mathrm{~mm}$ circular tube. They observed different trends between R123 and R134a in heat transfer coefficient. The flow boiling heat transfer of R123 shows that the heat transfer coefficients depend on mass velocity, heat flux and vapor quality. On the contrary, the heat transfer trends of $\mathrm{R} 134 \mathrm{a}$ are similar to those of macro-channels. The heat transfer coefficients are strongly dependent on heat flux and saturation pressure at low and intermediate vapor quality, but the effects of mass velocity

Corresponding author. Email: s_baba@aero.kyushu-u.ac.jp 
and vapor quality are insignificant. At high vapor quality, the mass velocity effect is dominant while the effects of heat flux and saturation pressure are small. Ong and Thome (2009) measured local heat transfer coefficient for R134a, R236fa and R245fa flowing in a single circular tube with $1.03 \mathrm{~mm}$. They modified an isolated bubble (IB)/coalescing bubble (CB)/annular flow map to investigate the influence of flow pattern on the heat transfer coefficient. They observed the heat transfer coefficients of R134a and R236fa increase with increasing heat flux in the IB flow regime at low mass velocity conditions. On the other hand, after a flow regime transition from $\mathrm{CB}$ to annular flow, the heat transfer of R236fa and R245fa increases with vapor quality and converge monotonically at higher vapor quality.

In flow boiling in mini-channels, back flow could be occurred because of rapid growth of bubbles in a confined cross section area of mini-tubes, resulting flow rate fluctuation. Flow boiling heat transfer characteristics in minichannels can change considerably by the existence of inlet flow rate fluctuation. Ohta et al. (2009) investigated experimentally the effect of flow fluctuation at the heated section inlet on flow boiling heat transfer and to clarify reasons for existing deviation in the heat transfer data for minichannels. It is important to pay attention to the experimental accuracy and to use a single circular mini-tube to compare heat transfer characteristics with those for normal size tubes.

The criteria for the classification of small channels have given by the researchers. Kew and Cornwell (1997) introduced a Confinement number $C o$ which is based on the definition of the Laplace constant and suggested the threshold criterion with limited data as

$$
C o=\left[\frac{\sigma}{g\left(\rho_{l}-\rho_{v}\right) d_{h}^{2}}\right]^{0.5}>0.5
$$

where, $\sigma$ is surface tension, $g$ is gravitational acceleration, $\rho_{l}$, and $\rho_{v}$ are liquid and vapor density and $d_{h}$ is hydraulic diameter of the channel. An alternative criterion to discriminate between micro and macroscale heat exchangers is that proposed by Mehendale et al. (2000) which is simply based on the hydraulic diameter. The hydraulic diameter range from 1 to $100 \mu \mathrm{m}$ is micro-heat exchangers, the range from $100 \mu \mathrm{m}$ to $1 \mathrm{~mm}$ is meso-heat exchangers, the range from $1 \mathrm{~mm}$ to $6 \mathrm{~mm}$ is compact heat exchangers, and values above $6 \mathrm{~mm}$ being conventional heat exchangers. Kandlikar (2002) employed the hydraulic diameter as an important parameter for defining the channels as follows: the hydraulic diameter range from 10 to $200 \mu \mathrm{m}$ is microchannels, the range from $200 \mu \mathrm{m}$ to $3 \mathrm{~mm}$ is minichannels and values above $3 \mathrm{~mm}$ being macroscale channels. Ong and Thome (2011) conducted the flow boiling experiment to clarify macro to microchannel transition in horizontal mini-tubes with I.D. 1.03, 2.20 and $3.04 \mathrm{~mm}$ using R134a, $\mathrm{R} 236 \mathrm{fa}$ and R245fa as test fluid. They proposed the criteria depend on the results from liquid film thickness measurements by using $C o$ as follow: $C o<0.3-0.4$ is macroscale flow, while $C o>1$ is symmetric microscale flow and the transition criterion is $0.3-0.4<C o<1$.

In the present paper, effects of tube orientation on flow boiling heat transfer characteristics were investigated for FC72 flowing in single mini-tubes with tube diameters of 0.13 and $0.51 \mathrm{~mm}$ to define boundaries on a dominant force regime map.

\section{DOMINANT FORCE REGIME MAP}

In order to clarify the influences of three major forces, following dimensionless parameters; Bond number Bo, Weber number We and Froude number $\mathrm{Fr}$ are defined here

$$
B o=\frac{\left(\rho_{l}-\rho_{v}\right) g d_{i}^{2}}{\sigma}
$$

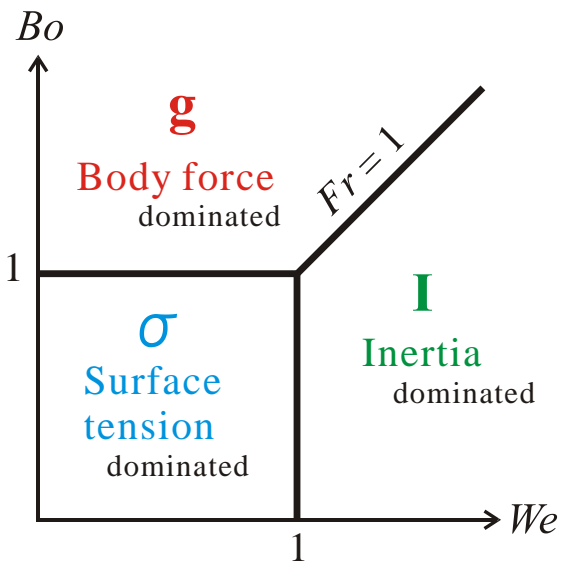

Fig. 1 Existing dominant force regime map. (Reynolds et al., 1964)

$$
\begin{aligned}
& W e=\frac{\rho_{m} u_{m}^{2} d_{i}}{\sigma}=\frac{G^{2} d_{i}}{\rho_{m} \sigma} \\
& F r=\sqrt{\frac{W e}{B o}}=\frac{G}{\sqrt{\rho_{m}\left(\rho_{l}-\rho_{v}\right) g d_{i}}}
\end{aligned}
$$

where, $d_{i}$ : tube inner diameter, $G$ : mass velocity, $u_{m}$ : mean velocity, $\rho_{m}=$ $1 /\left[x / \rho_{v}+(1-x) / \rho_{l}\right]$ : mean density of liquid and vapor, $x$ : vapor quality and $\sigma$ : surface tension. Therefore, $\mathrm{Bo}, \mathrm{We}, \mathrm{Fr}$ represent ratios of buoyancy to surface tension, inertia to surface tension and inertia to buoyancy, respectively. Fig. 1 shows the existing map for dominant force regimes proposed by Reynolds et al. (1964) for the dynamic motion of a liquidgas system in low gravity. The influence of inertia is varied by the change of vapor quality, i.e. ratio of vapor mass flow rate to the total, under a constant mass velocity, where the velocity of liquid-vapor mixtures is increased with increasing vapor quality

There are four points to be clarified concerning the present regime map.

1. Boundaries of regimes are doubtful.

2. Definitions of parameters should be revised.

3. Parameters and boundaries should be changed by different targets such as heat transfer coefficient, flow patterns, pressure drop and critical heat flux.

4. Influence of vapor quality is unknown. Increase in vapor quality increases inertia force due to the increase in liquidvapor mixture velocity despite of decrease in mixture density.

It is doubtful that the effect of gravity level is equivalent to the effect of direction of the gravity vector on the definition of regime boundary between the body force dominated and the surface tension dominated through Bond number. The microgravity experiments are useful for the verification of the effect of gravity level on these regimes. In further studies, the results obtained under microgravity conditions are to be reflected to confirm the effect of gravity level on the boundaries at very low Bond numbers.

\section{EXPERIMENTAL APPARATUS}

The structure of experimental setup is shown in Fig.2. The system is operated as an open system. Subcooled liquid is supplied from a syringe pump through a conduit monitoring flow fluctuation and a filter before the inlet of a test section. Flow fluctuation was minimized by employing a high-powered syringe pump. In order to minimize the flow fluctuation due to the flow resistance change resulting from the bubble growth in a small diameter tube, a high-powered syringe pump is 


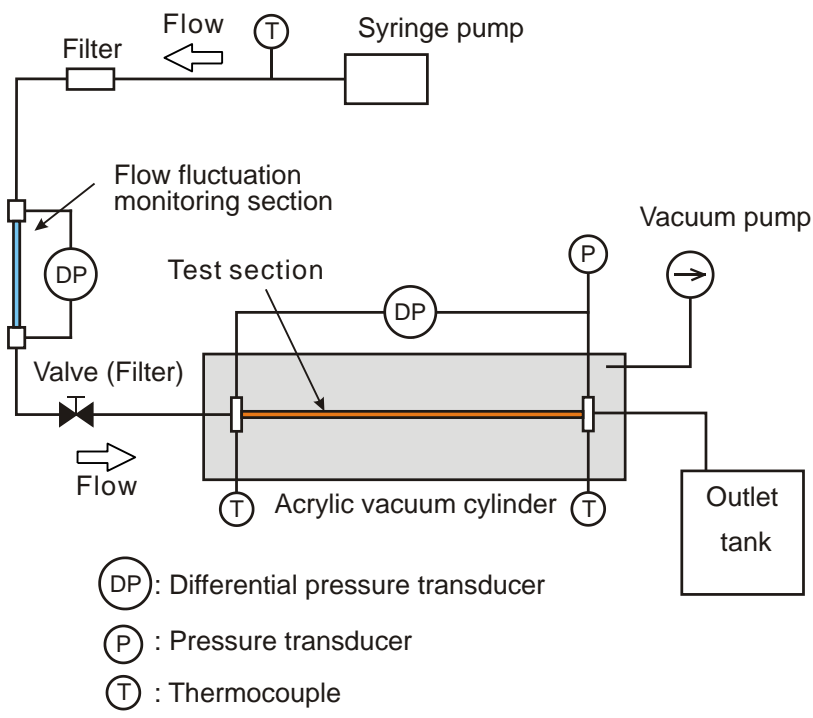

Fig. 2 Experimental setup.

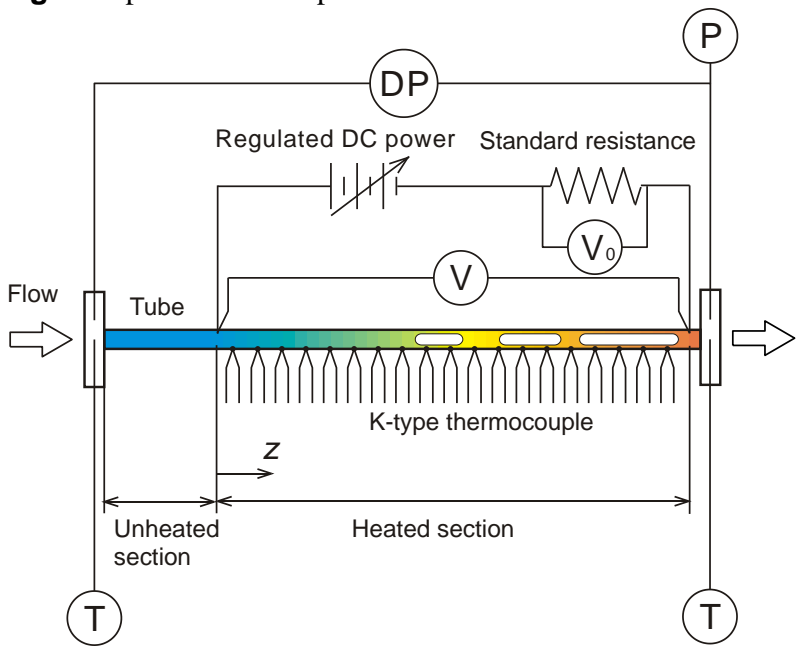

Fig. 3 Test section.

Table 1 Dimension of test tubes.

\begin{tabular}{c|c|c|c|c}
\hline $\begin{array}{c}\text { Type of } \\
\text { tube }\end{array}$ & $\begin{array}{c}\text { Inner } \\
\text { diameter } \\
d_{i} \mathrm{~mm}\end{array}$ & $\begin{array}{c}\text { Outer } \\
\text { diameter } \\
d_{o} \mathrm{~mm}\end{array}$ & $\begin{array}{c}\text { Heated } \\
\text { length } \mathrm{mm}\end{array}$ & $\begin{array}{c}\text { Unheated } \\
\text { length } \mathrm{mm}\end{array}$ \\
\hline $\mathrm{A}$ & 0.51 & 0.81 & 200 & 37 \\
\hline $\mathrm{B}$ & 0.13 & 0.31 & 100 & 30 \\
\hline
\end{tabular}

connected. The liquid flow rate and its fluctuation at the inlet of test section are monitored by the measurement of pressure drop across a non-heated small circular tube with an inner diameter $d_{i}=0.51 \mathrm{~mm}$ and a length $l=100 \mathrm{~mm}$.

The test section is shown in Fig.3. To introduce electric current for joule heating from a regulated DC power supply, copper electrodes are soldered on the tube outer surfaces at both ends of the heated section. To eliminate the effects of voltage drops at the junctions of electrodes and at lead wires, two voltage taps are additionally soldered just inside of the electrodes for electric current, and the heating rate is evaluated with high accuracy based on the power input. In order to keep electrical insulation, all tubes connected to the test section are made of Teflon.

Table 1 lists the dimensions of the two test tubes employed here. The unheated section operates as a hydrodynamic entrance region, and the fully developed flow is established at the inlet of the heated section. Nineteen K-type bare thermocouples with a diameter of $0.08 \mathrm{~mm}$ are
Table 2 Experimental conditions.

\begin{tabular}{l|l}
\hline Test fluid & FC72(deaerated) \\
\hline Inlet subcooling & $\Delta T_{\text {sub }}=32-33 \mathrm{~K}$ \\
\hline Mass velocity & $G=50-200 \mathrm{~kg} / \mathrm{m}^{2} \mathrm{~s}$ \\
\hline Heat flux & $q=2.6-16.4 \mathrm{~kW} / \mathrm{m}^{2}$ \\
\hline Outlet pressure & $P_{\text {out }}=0.10-0.11 \mathrm{MPa}$ \\
\hline Flow direction & $\begin{array}{l}\text { Horizontal, } \\
\text { Vertical upward, } \\
\end{array}$ \\
& Vertical downward, \\
\hline
\end{tabular}

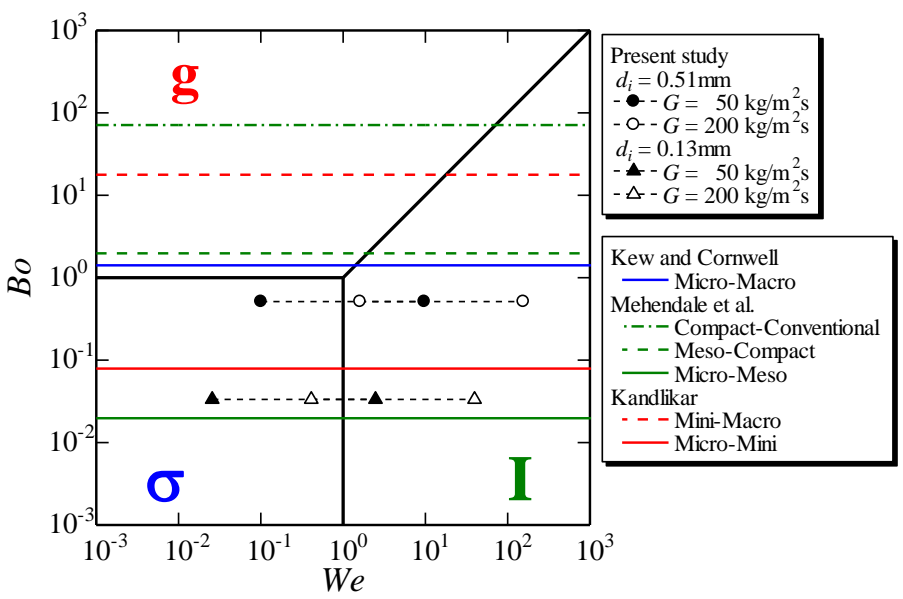

Fig. 4 The experimental condition in present study and existing boundary for the classification of small channels proposed by Kew and Cornwell (1997), Mehendale et al. (2000) and Kandlikar (2002) on dominant force regime map for FC72.

directly soldered to the outer surface of the tube along the entire heated section. The values of electromotive force of bare thermocouples are obtained by subtracting the additional voltages, which is unavoidably picked up due to the application of heating current directly to the tube wall, from the measured values. Both ends of the test tube are connected to small polycarbonate blocks with pressure taps, and K-type sheathed thermocouples are inserted in them. To minimize the heat loss from the heated tube and to establish steady state in a short time, the test section is installed in an acrylic vacuum cylinder with an inside diameter of $190 \mathrm{~mm}$ and a length of $350 \mathrm{~mm}$. In all experimental conditions tested, only a few minutes are required to obtain the data regarded as that of steady-state condition, which is judged by monitoring electromotive force of all thermocouples. The pressure drops across the test section and across the section monitoring flow fluctuation are measured by the differential pressure transducers. In the present experiments, the pressure at the outlet of the test section is kept at near atmospheric pressure, where the saturation temperature is $56{ }^{\circ} \mathrm{C}$ at $0.1 \mathrm{MPa}$ for fluorinert FC72 employed as a test fluid. The outlet pressure of the test section is varied to some extent as $0.10-0.11 \mathrm{MPa}$, depending on the pressure drop at downstream. Flow boiling heat transfer of FC72 in a small diameter tube is influenced by dissolved air, as mentioned in our previous report (Ohta et al., 2009). Test fluid in the reservoir was initially degassed by vacuum deaeration for more than 10 minutes. Compressible gas was completely removed from the components of the test loop. Then, the deaerated test fluid was filled with the test loop from the reservoir. Experimental conditions are shown in Table 2 .

If the regime map is described by using Bond, Weber and Froude numbers above mentioned, the boundary of dominant forces of body force and inertia is examined by using the mini-tube of the larger 
diameter employed here at a constant Bond number $B o=5.1 \times 10^{-1}$, and the boundary of surface tension and inertia by using the mini-tube of smaller diameter at $B o=3.3 \times 10^{-2}$. Figure 4 shows experimental conditions in present study and existing boundary for the classification of small channels proposed by Kew and Cornwell, Mehendale et al. and Kandlikar on dominant force regime map.

\section{DATA TREATMENT}

The distribution of inner wall temperature, heat flux, fluid temperature, vapor quality, and heat transfer coefficient along the heated section is calculated as discrete values at each location of nineteen thermocouples based on the measured values of outer wall temperatures, flow rate, inlet liquid temperature, and pressures. The local heat generation rate is calculated by using a value of electric current and local electric resistance of stainless steel tube. The local electric resistance is evaluated at the local temperature using the temperature coefficient of stainless steel. Because the electric resistance increases with an increase in temperature, the heat generation per unit length is slightly larger in the downstream of the heated section by $1 \%$ at the highest heat flux tested. The heat loss from the outer tube wall to the ambient is evaluated by the difference between the outer wall temperature and ambient temperature in the vacuum cylinder, which is calibrated in advance. By the introduction of vacuum cylinder and thin thermocouples, the heat loss is less than $50 \%$ of the heat input even at the lowest heat flux tested. Because the ratio of the tube wall thickness to the axial distance between the positions of neighboring thermocouples is small, the heat transfer due to the axial conduction across the tube wall is negligible to the heat transferred to test fluid. The inner wall temperature and the inner wall heat flux at each thermocouple location are evaluated by the radial heat conduction from the measured outer wall temperature and the local heat generation rate, taking into account the heat loss.

The inlet liquid temperature is measured by a K-type sheathed thermocouple inserted in the inlet Teflon block. The mean local fluid enthalpy $h$ at each thermocouple location is calculated from the heat balance equation. The local vapor quality $x$ assuming thermal equilibrium is calculated by

$$
x=\frac{h-h_{l}}{h_{v}-h_{l}}
$$

where $h_{l}$ and $h_{v}$ are enthalpies of saturated liquid and saturated vapor, respectively, evaluated at the local value of pressure. The local heat transfer coefficient $\alpha$ at the location of each thermocouple is defined by

$$
\alpha=\frac{q}{T_{w}-T_{f}}
$$

where, $q$ : inner wall heat flux to fluid, $T_{w}$ : inner wall temperature, $T_{f}$ : mean fluid temperature. $T_{f}$ is evaluated from the heat balance equation. The saturation temperature $T_{\text {sat }}$ is used as $T_{f}$ in the quality region $x>0$. A value of two-phase pressure drop in the quality region is obtained by subtracting the value in the unheated section and the subcooled region from the pressure drop across the entire test section. The single-phase pressure drop is evaluated in the subcooled region, ignoring the possibility of partial boiling. In the quality region, linear pressure drop is assumed using the pressures at the end of the subcooled region and at the outlet of the test section. Distribution of saturation temperature in the quality region is obtained by the pressure distribution. All of the instruments used are carefully calibrated. The uncertainty in temperature measurement is $\pm 0.15 \mathrm{~K}$, pressure measurement $\pm 0.04 \mathrm{kPa}$, and flow rate setting $\pm 0.35 \%$. The accuracy of heat transfer coefficients is evaluated to be $\pm 20 \%$.

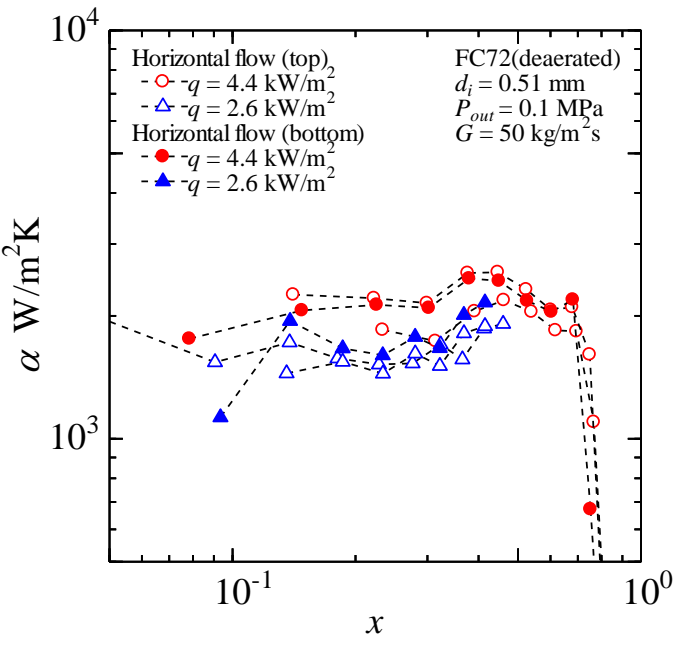

(a) $G=50 \mathrm{~kg} / \mathrm{m}^{2} \mathrm{~s}$

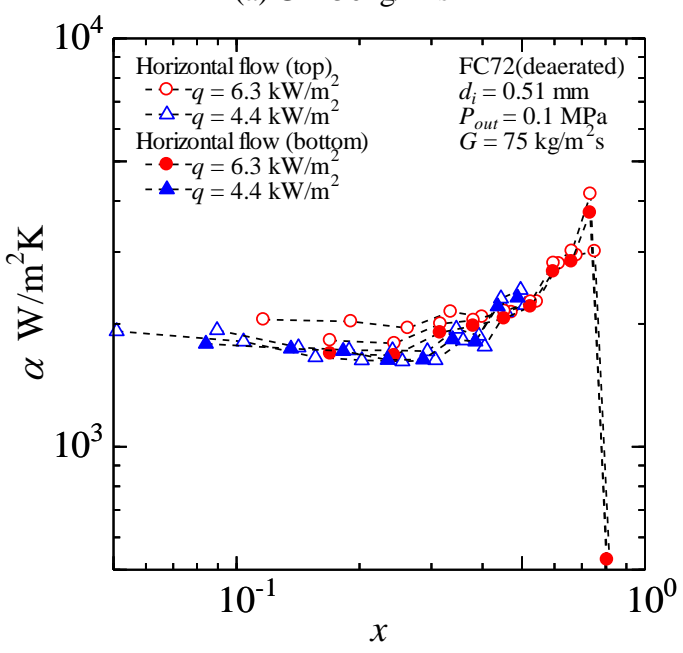

(b) $G=75 \mathrm{~kg} / \mathrm{m}^{2} \mathrm{~s}$

Fig. 5 Heat transfer coefficient versus vapor quality with top and bottom of the tube with $d_{i}=0.51 \mathrm{~mm}$.

\section{EXPERIMENTAL RESULTS AND DISCUSSION}

\subsection{Effect of circumferential location of the tube on the heat transfer coefficient}

Figure 5 shows the heat transfer coefficients as a function of vapor quality with top and bottom of the tube under low mass velocity conditions, $G=50,75 \mathrm{~kg} / \mathrm{m}^{2} \mathrm{~s}$, in which effects of buoyancy on bubbles seems to be large. In the entire range of vapor quality at $G=50 \mathrm{~kg} / \mathrm{m}^{2} \mathrm{~s}$ and in low vapor quality $x<0.4$, at $G=75 \mathrm{~kg} / \mathrm{m}^{2}$ s, heat transfer coefficient is independent of vapor quality suggesting nucleate boiling dominant region. On the other hand, heat transfer coefficient is dependent of vapor quality suggesting that two-phase forced convection dominated the heat transfer in moderate vapor quality at $G=75 \mathrm{~kg} / \mathrm{m}^{2} \mathrm{~s}$, and heat transfer deterioration due to dryout is observed at high vapor quality. The influence of measurement point in a circumferential direction of the tube is not observed in the entire range of vapor quality. This result provides evidence that the tube wall thickness is large enough to realize the uniform temperature distribution along the circumferential direction of the tube. 


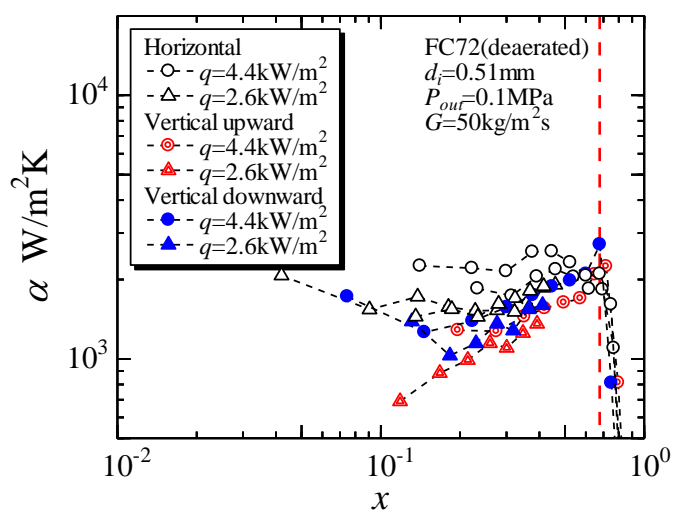

(a) $G=50 \mathrm{~kg} / \mathrm{m}^{2} \mathrm{~s}$

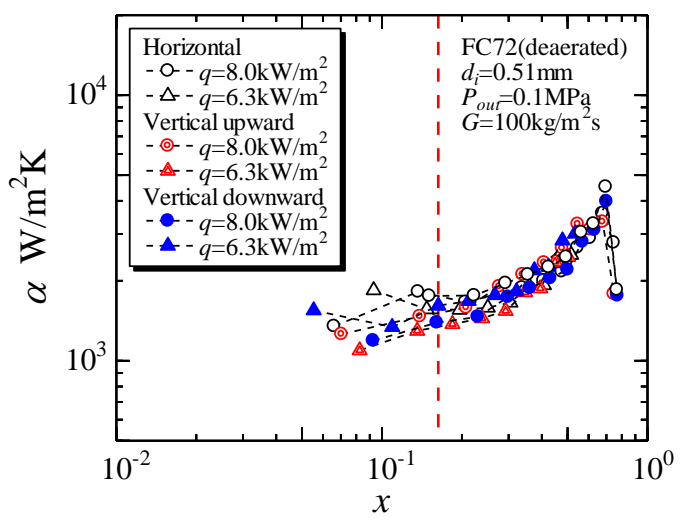

(c) $G=100 \mathrm{~kg} / \mathrm{m}^{2} \mathrm{~s}$

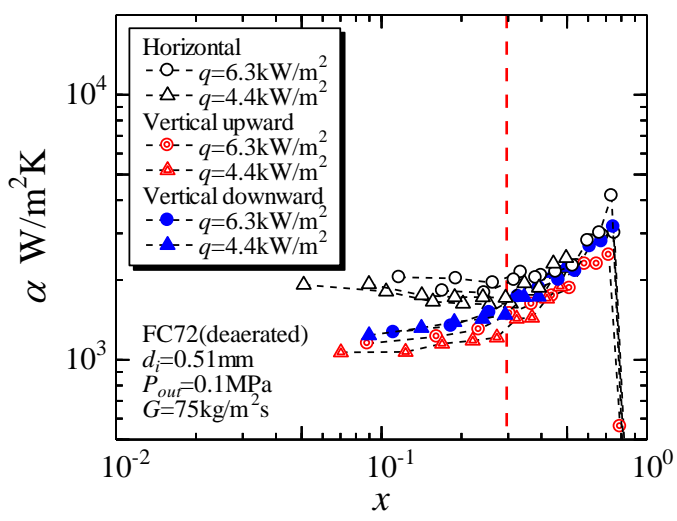

(b) $G=75 \mathrm{~kg} / \mathrm{m}^{2} \mathrm{~s}$

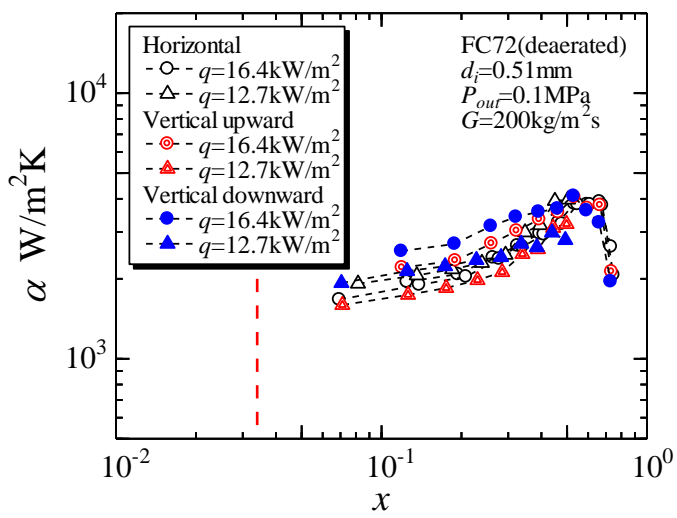

(d) $G=200 \mathrm{~kg} / \mathrm{m}^{2} \mathrm{~s}$

Fig. 6 Heat transfer coefficient versus vapor quality for $d_{i}=0.51 \mathrm{~mm}$.

\subsection{Effect of tube orientation on the heat transfer coefficient}

The relation between the heat transfer coefficient and vapor quality for $d_{i}=0.51 \mathrm{~mm}$ at $G=50-200 \mathrm{~kg} / \mathrm{m}^{2} \mathrm{~s}$ is shown in Fig.6. In the entire range of vapor quality at $G=50 \mathrm{~kg} / \mathrm{m}^{2}$ s and in low vapor quality $x<$ 0.4 , at $G=75 \mathrm{~kg} / \mathrm{m}^{2} \mathrm{~s}$, heat transfer coefficients were influenced by tube orientation, heat transfer coefficients in the horizontal tube are higher than those in vertical tubes. Furthermore, heat transfer coefficients are constant with vapor quality for the horizontal tube, while heat transfer coefficients are increase with increasing vapor quality for the vertical

tube. On the other hand, the effect of tube orientation were decreased under high vapor quality $x>0.3$ at $G=75 \mathrm{~kg} / \mathrm{m}^{2} \mathrm{~s}$ and in the entire range of vapor quality at $G=100,200 \mathrm{~kg} / \mathrm{m}^{2} \mathrm{~s}$. In the horizontal tube under low vapor quality condition, the local liquid film thickness at the tube top becomes thinner because the position of elongated bubbles is influenced by buoyancy (Han and Shikazono, 2009). Because enhancement of heat transfer at the top overcomes the deterioration at the bottom, the heat transfer coefficients in the horizontal tube are higher than those in vertical tubes. On the other hand, under high vapor quality conditions, there is uniform distribution of liquid film thickness for each tube orientation. The effect of mass velocity and heat flux is not confirmed because the experiments were operated within narrow range of heat flux to prevent the temperature excursion due to dryout near the outlet of the tube. It is need to perform experiments under higher heat flux conditions by altering tube length in further studies. The relation between the heat transfer coefficient and Froude number which represents ratio of inertia to buoyancy for $d_{i}=0.51 \mathrm{~mm}$ tube for all mass velocity conditions is shown in Fig.7. Under low inertia conditions at Froude number $F r<4$, the heat transfer coefficient is independent on vapor quality in the horizontal tube. The results indicated that the boundary between the body force dominated and the inertia dominated regimes is given by Froude number as $F r \approx 4$ (shown as red vertical dashed line in Fig. 6 and 7).

The relation between heat transfer coefficient and vapor quality for $d_{i}=0.13 \mathrm{~mm}$ at $G=50-200 \mathrm{~kg} / \mathrm{m}^{2} \mathrm{~s}$ is shown in Fig.8. Although there is scattering in the heat transfer data, almost no effect of tube orientation on heat transfer coefficients is observed for all combinations of mass velocity and vapor quality. Under low mass velocity conditions at $G=$ $50,75 \mathrm{~kg} / \mathrm{m}^{2} \mathrm{~s}$, heat transfer coefficients are independent of mass velocity and vapor quality, while the effect of vapor quality on heat transfer coefficients are observed under high mass velocity conditions at $G=200 \mathrm{~kg} / \mathrm{m}^{2} \mathrm{~s}$. The relation between heat transfer coefficient and Weber number for $d_{i}=0.13 \mathrm{~mm}$ under all mass velocity conditions is shown in Fig.9. Under low inertia conditions at Weber number $W e<5$, heat transfer coefficients are independent of mass velocity and vapor quality, while the effect of vapor quality on heat transfer coefficients are observed for $W e>5$. The results implies the boundary between the surface tension dominated and inertia dominated regimes is represented by $W e \approx 5$ (shown as red vertical dashed line in Fig. 8 and 9).

The boundaries on the two-dimensional regime map reflecting both results are shown in Fig.10. In addition, the boundary between the surface tension dominated and the body force dominated regimes is approximately evaluated as $B o \approx 3.1 \times 10^{-1}$ from the crossing point of the two boundary lines. This value located in the range of $3.3 \times 10^{-2}<B o<$ $5.1 \times 10^{-1}$ is consistent with the boundary between the surface tension dominated and the body force dominated regimes which were confirmed for the employed smaller mini-tube $\left(B o=3.3 \times 10^{-2}\right)$ and the larger mini-tube $\left(B o=5.1 \times 10^{-1}\right)$, respectively, under low inertia conditions. 


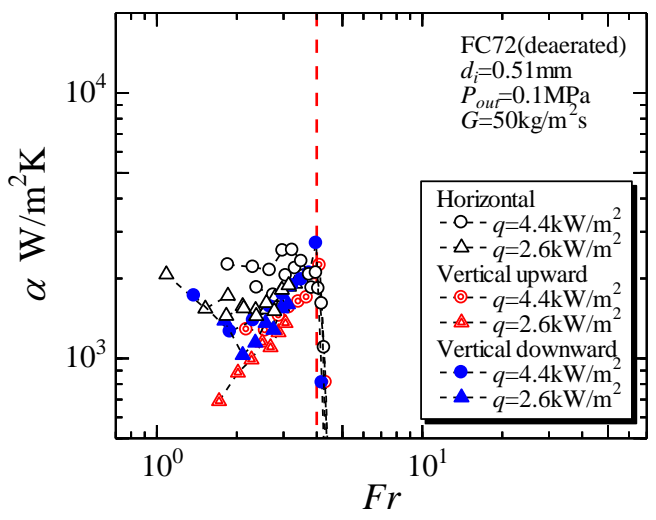

(a) $G=50 \mathrm{~kg} / \mathrm{m}^{2} \mathrm{~s}$

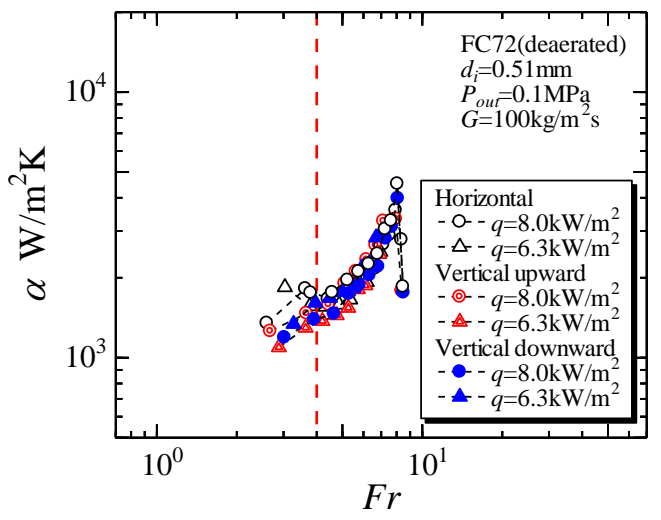

(c) $G=100 \mathrm{~kg} / \mathrm{m}^{2} \mathrm{~s}$

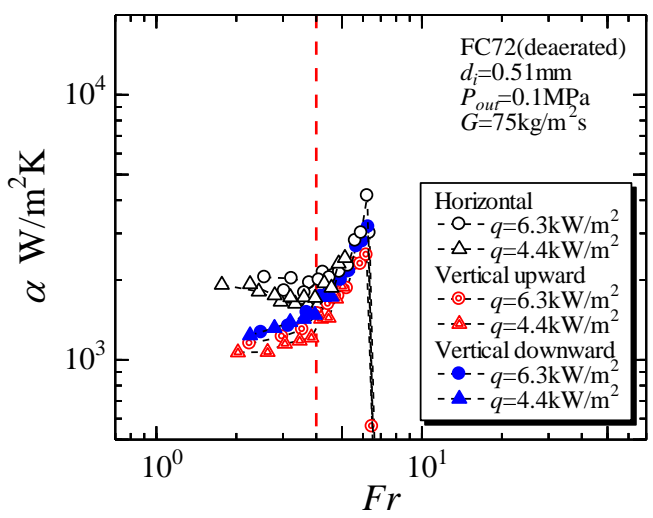

(b) $G=75 \mathrm{~kg} / \mathrm{m}^{2} \mathrm{~s}$

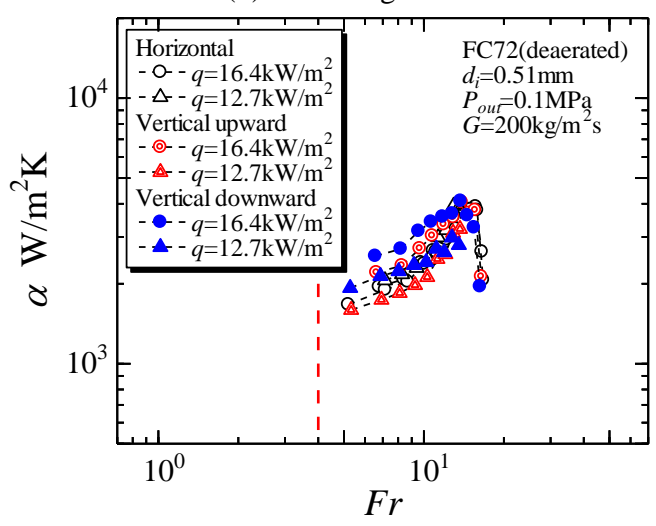

(d) $G=200 \mathrm{~kg} / \mathrm{m}^{2} \mathrm{~s}$

Fig. 7 Heat transfer coefficient versus Froude number for $d_{i}=0.51 \mathrm{~mm}$.

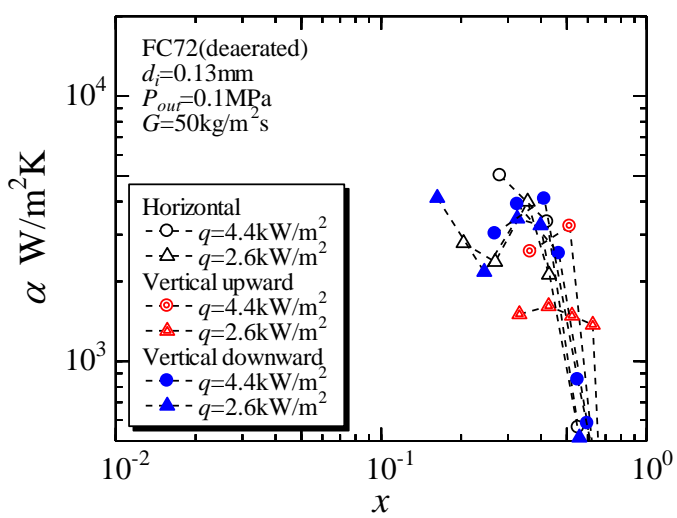

(a) $G=50 \mathrm{~kg} / \mathrm{m}^{2} \mathrm{~s}$

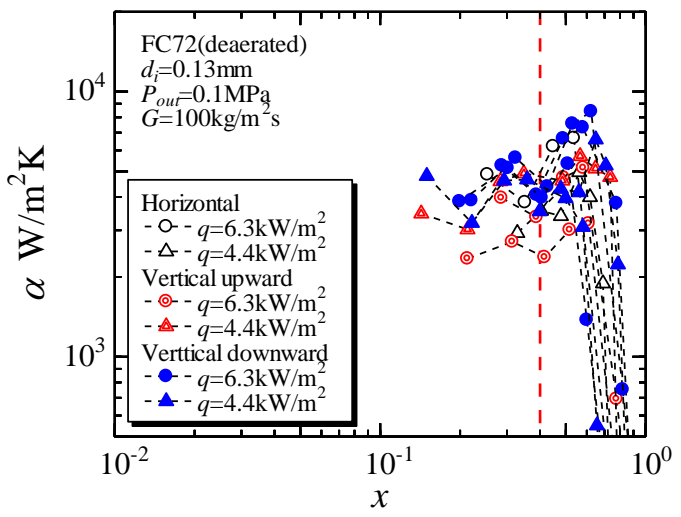

(c) $G=100 \mathrm{~kg} / \mathrm{m}^{2} \mathrm{~s}$

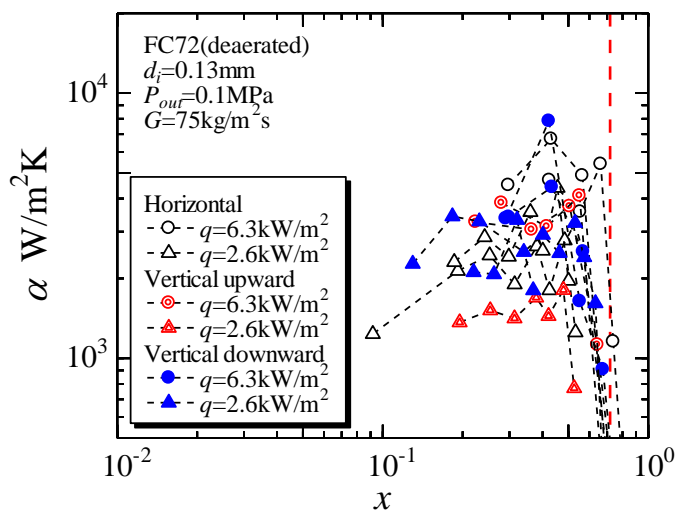

(b) $G=75 \mathrm{~kg} / \mathrm{m}^{2} \mathrm{~s}$

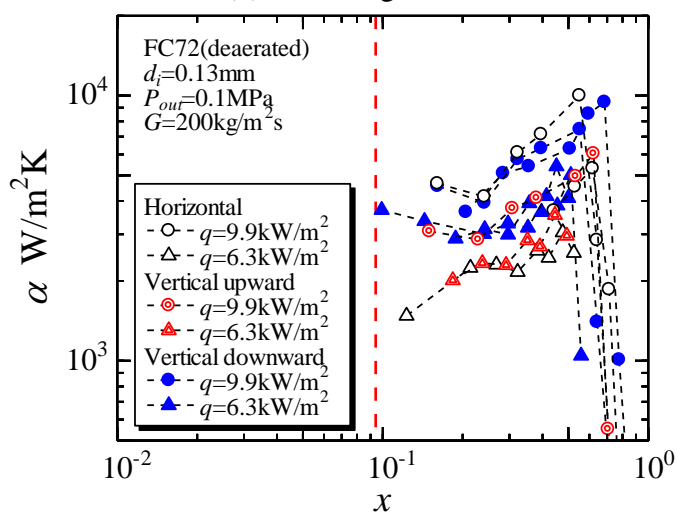

(d) $G=200 \mathrm{~kg} / \mathrm{m}^{2} \mathrm{~s}$

Fig. 8 Heat transfer coefficient versus vapor quality for $d_{i}=0.13 \mathrm{~mm}$. 


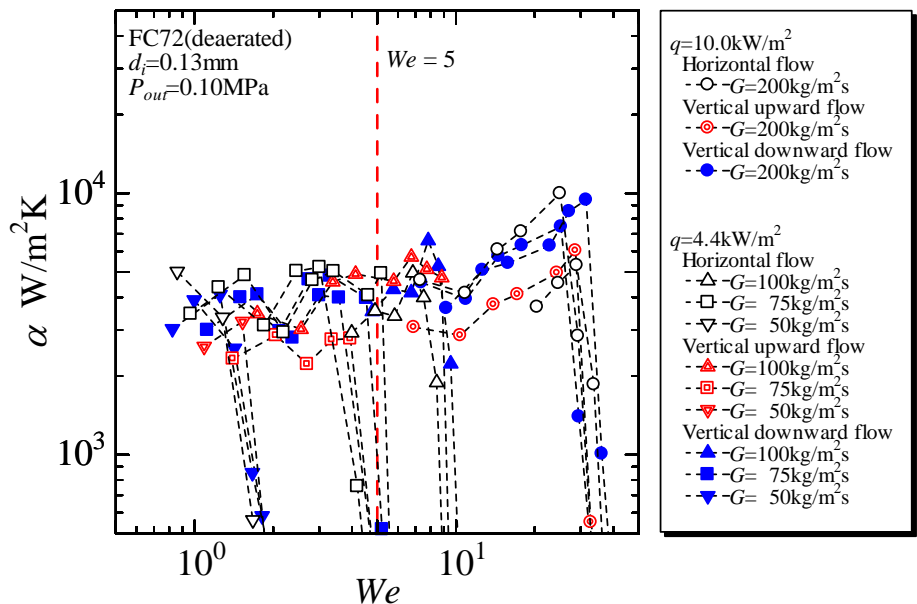

Fig. 9 Heat transfer coefficient versus Weber number for $d_{i}=0.13 \mathrm{~mm}$ under all mass velocity conditions.

\section{CONCLUSIONS}

Effects of tube orientations, i.e. vertical upward flow, vertical downward flow and horizontal flow, on flow boiling heat transfer characteristics are investigated for FC72 flowing in single mini-tubes with inner diameters of 0.13 and $0.51 \mathrm{~mm}$ to establish a reliable dominant force regime map. The results are summarized as follows.

1. For the tube diameter of $0.51 \mathrm{~mm}$, under low inertia conditions at Froude number $F r<4$, heat transfer coefficients were influenced by the tube orientation, while the heat transfer coefficients were almost independent of the orientation for $F r>4$.

2. For the tube diameter of $0.13 \mathrm{~mm}$, almost no effect of tube orientation was observed for all combinations of mass velocity and vapor quality, and heat transfer coefficients were independent of vapor quality under low inertia conditions at Weber number We $<5$.

3. The boundary between the body force dominated and the inertia force dominated regimes was given by Froude number as $\mathrm{Fr} \approx 4$, and the boundary between the surface tension dominated and the inertia force dominated regimes was represented by $\mathrm{We} \approx 5$.

\section{NOMENCLATURE}

$\begin{array}{ll}\text { Bo } & \text { Bond number } \\ \text { Co } & \text { Confinement number } \\ d & \text { diameter }(\mathrm{m}) \\ F r & \text { Froude number } \\ G & \text { mass velocity }\left(\mathrm{kg} / \mathrm{m}^{2} \mathrm{~s}\right) \\ g & \text { gravitational acceleration }(\mathrm{m} / \mathrm{s}) \\ h & \text { specific enthalpy }(\mathrm{J} / \mathrm{kg}) \\ l & \text { tube length }(\mathrm{m}) \\ P & \text { pressure }(\mathrm{Pa}) \\ q & \text { heat flux }\left(\mathrm{W} / \mathrm{m}^{2}\right) \\ T & \text { temperature }(\mathrm{K}) \\ W e & \text { Weber number } \\ x & \text { vapor quality } \\ \text { Greek } & \text { Symbols } \\ \alpha & \text { heat transfer coefficient }\left(\mathrm{W} / \mathrm{m}^{2} \mathrm{~K}\right) \\ \rho & \text { density }\left(\mathrm{kg} / \mathrm{m}^{3}\right) \\ \sigma & \text { surface tension }(\mathrm{N} / \mathrm{m})\end{array}$

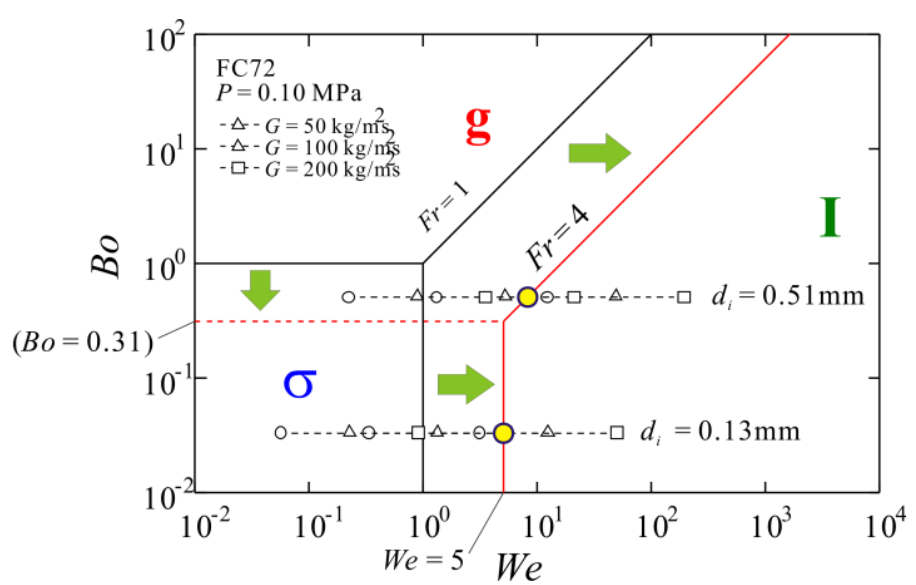

Fig. 10 Proposed boundaries on dominant force regime map.

$\begin{array}{ll}\text { Subscripts } & \\ \mathrm{f} & \text { fluid } \\ \mathrm{h} & \text { hydraulic } \\ \mathrm{i} & \text { inner } \\ \text { in } & \text { inlet } \\ \mathrm{l} & \text { liquid } \\ \mathrm{m} & \text { mean } \\ \mathrm{o} & \text { outer } \\ \text { sat } & \text { saturated } \\ \text { sub } & \text { subcooling } \\ \mathrm{v} & \text { vapor } \\ \mathrm{w} & \text { inner wall }\end{array}$

\section{REFERENCES}

Bao, Z.Y., Fletcher, D.F. and Haynes, B.S., 2000, "Flow Boiling Heat Transfer of Freon R11 and HCFC123 in Narrow Passages," International Journal of Heat and Mass Transfer, 43(18), 3347-3358. http://dx.doi.org/10.1016/S0017-9310(99)00379-8

Han, Y. and Shikazono, N., 2009, "Measurement of the Liquid Film Thickness in Micro Tube Slug Flow," International Journal of Heat Fluid Flow, 30(5), 842-853. http://dx.doi.org/10.1016/j.ijheatfluidflow.2009.02.019

Kandlikar, S.G., 2002, "Fundamental Issues Related to Flow Boiling in Minichannels and Microchannels," Experimental Thermal and Fluid Science, 26(2-4), 389-407.

http://dx.doi.org/10.1016/S0894-1777(02)00150-4

Kew, P.A. and Cornwell, K., 1997, "Correlations for the Prediction of Boiling Heat Transfer in Small-Diameter Channels," Applied Thermal Engineering, 17(8-10), 705-715. http://dx.doi.org/10.1016/S1359-4311(96)00071-3

Lazarek, G.M. and Black, S.H., 1982, "Evaporative Heat Transfer, Pressure Drop and Critical Heat Flux in a Small Vertical Tube with R113," International Journal of Heat and Mass Transfer, 25(7), 945-960. http://dx.doi.org/10.1016/0017-9310(82)90070-9

Lin, S., Kew, P.A. and Cornwell, K., 2001, "Two-phase Heat Transfer to a Refrigerant in a $1 \mathrm{~mm}$ Diameter Tube," International Journal of Refrigeration, 24(1), 51-56. http://dx.doi.org/10.1016/S0140-7007(00)00057-8 
Mehendale, S.S., Jacobi, A.M. and Shah, R.K., 2000, "Fluid Flow and Heat Transfer at Micro- and Meso-Scales with Application to Heat Exchanger Design," Applied Mechanics Reviews, 53(7), 175-193. http://dx.doi.org/10.1115/1.3097347

Ohta, H., Inoue, K., Ando, M. and Watanabe, K., 2009, "Experimental Investigation on Observed Scattering in Heat Transfer Characteristics for Flow Boiling in a Small Diameter Tube," Heat transfer engineering, 30(1-2), 19-27.

http://dx.doi.org/10.1080/01457630802290080

Ong, C.L. and Thome, J.R., 2009, "Flow Boiling Heat Transfer of $\mathrm{R} 134 \mathrm{a}, \mathrm{R} 236 \mathrm{fa}$ and R245fa in a Horizontal $1.030 \mathrm{~mm}$ Circular Channel," Experimental Thermal and Fluid Science, 33(4), 651-663. http://dx.doi.org/10.1016/j.expthermflusci.2009.01.002

Ong, C.L., and Thome, J.R., 2011, "Macro-to-Microchannel Transition in Two-phase Flow: Part 1 - Two-phase Flow Patterns and Film Thickness Measurements," Experimental Thermal and Fluid Science, 35(1), 37-47.

http://dx.doi.org/10.1016/j.expthermflusci.2010.08.004

Owhaib, W., Martin-Callizo, C. and Palm, B., 2004, "Evaporative Heat Transfer in Vertical Circular Microchannels," Applied Thermal Engineering, 24(8-9), 1241-1253. http://dx.doi.org/10.1016/j.applthermaleng.2003.12.030

Reynolds, W.C., Saad, M.A. and Satterlee, H.M., 1964, "Capillary Hydrostatics and Hydrodynamics at Low g", Technical Report LG-3, Dept. Mechanical Engineering, Stanford University.

Saisorn, S., Kaew-On, J. and Wongwises, S., 2010, "Flow Pattern and Heat Transfer Characteristics of R-134a Refrigerant during Flow Boiling in a Horizontal Circular Mini-channel," International Journal of Heat and Mass Transfer, 53(19-20), 4023-4038. http://dx.doi.org/10.1016/j.ijheatmasstransfer.2010.05.022
Saitoh, S., Daiguji, H. and Hihara, E., 2005, "Effect of Tube Diameter on Boiling Heat Transfer of R-134a in Horizontal Small-Diameter Tubes," International Journal of Heat and Mass Transfer, 48(23-24), 4973-4984.

http://dx.doi.org/10.1016/j.ijheatmasstransfer.2005.03.035

In, S. and Jeong, S., 2009, "Flow Boiling Heat Transfer Characteristics of R123 and R134a in a Micro-channel," International Journal of Multiphase Flow, 35(11), 987-1000.

http://dx.doi.org/10.1016/j.ijmultiphaseflow.2009.07.003

Shiferaw, D., Karayiannis, T.G. and Kenning, D.B.R., 2009, "Flow Boiling in a $1.1 \mathrm{~mm}$ Tube with R134a: Experimental Results and Comparison with Model," International Journal of Thermal Sciences, 48(2), 331-341. http://dx.doi.org/10.1016/j.ijthermalsci.2008.02.009

Tran, T.N., Wambsganss M.W. and France, D.M., 1996, "Small Circular- and Rectangular-Channel Boiling with Two Refrigerants," International Journal of Multiphase Flow, 22(3), 485-498. http://dx.doi.org/10.1016/0301-9322(96)00002-X

Yen, T., Kasagi, N. and Suzuki, Y., 2003, "Forced Convective Boiling Heat Transfer in Microtubes at Low Mass and Heat Fluxes," International Journal of Multiphase Flow, 29(12), 1771-1792. http://dx.doi.org/10.1016/j.ijmultiphaseflow.2003.09.004

Yen, T., Shoji, M., Takemura, F., Suzuki, Y. and Kasagi, N., 2006, "Visualization of Convective Boiling Heat Transfer in Single Microchannels with Different Shaped Cross-Sections," International Journal of Heat and Mass Transfer, 49(21-22), 3884-3894. http://dx.doi.org/10.1016/i.ijheatmasstransfer.2005.12.024 